\title{
Effect of the purification treatment on the valorization of natural cellulosic residues as fillers in PHB-based composites for short shelf life applications
}

\author{
Estefanía Lidón Sánchez-Safont ${ }^{1}$, Abdulaziz Aldureid ${ }^{1}$, José María Lagarón ${ }^{2}$, José Gámez-Pérez ${ }^{1}$, \\ Luis Cabedo ${ }^{1 *}$
}

1. Polymers and Advanced Materials Group (PIMA), Universitat Jaume I (UII), Av. de Vicent Sos Baynat s/n, 12071 Castelló, Spain

2. bNovel Materials and Nanotechnology Group, Institute of Agrochemistry and Food Technology (IATA), Spanish National Research Council (CSIC), Calle Catedrático Agustín Escardino Benlloch 7, 46980 Paterna, Spain

\begin{abstract}
In this work the effect of a combined $\mathrm{NaOH}+$ peracetic acid (PAA) purification treatment on the valorization of almond shell (AS) and rice husk (RH) lignocellulosic residues as fillers in PHB-based composites for short shelf life applications has been studied. The efficiency of the treatment at removing the non cellulosic components of the fibers has been evaluated by SEM, FTIR, WAXS and TGA taking a commercial cellulose as reference. The influence of the untreated and treated fibers on the morphology, thermal, crystallization, tensile properties, fracture toughness and dynamo mechanical behavior of the PHB/fiber composites has been studied. The treatment has demonstrated its ability at removing the lignin, hemicelluloses and waxes allowing the obtention of fibers with relative crystallinity, thermal stability and composition similar to the commercial cellulose. The different agro-food based lignocellulosic residues used resulted in two suitable reinforcing fillers for a PHB matrix showing the composites prepared with the treated fibers better thermal and mechanical performance with respect to those prepared with the untreated ones.
\end{abstract}

\section{Keywords}

PHB, natural fiber, cellulose, biocomposite, waste valorization 


\section{Graphical abstract}

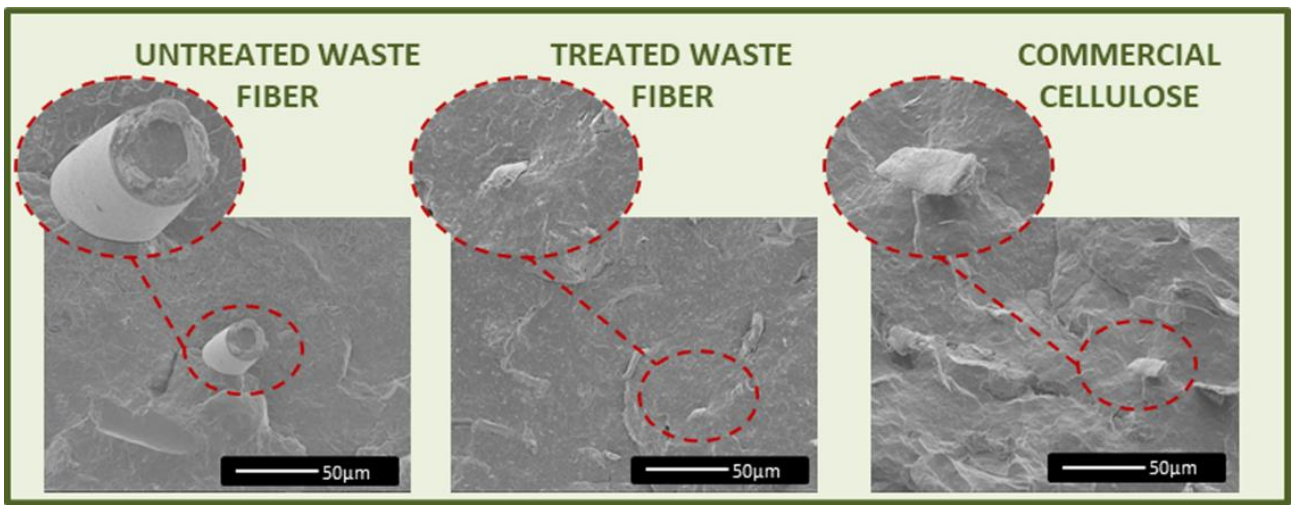

\section{State of novelty}

The manuscript explores the valorization of agrocellulosic wastes for the obtention of low cost biocomposites for short shelf life applications.

\section{Introduction}

The growing concern for the environment and the increasingly restrictive environmental directives results in an urgent need to find sustainable alternatives to conventional plastics. Particularly, in short shelf life applications or single-use products (e.g. in packaging or tableware articles) biodegradable or compostable materials pose as especially appropriate candidates. Within this context, biopolymers are called to be the ideal substitutes to the so-called "commodities" [1]. Concretely, polyhydroxyalkanoates (PHAs) have aroused great interest in these applicability fields and good proof of this is the large number of related publications that exist in literature [2-5].

In case of polyhydroxybutyrate (PHB) the main reasons that make it attractive for these type of applications are its bio-based origin, full biodisintegrability and compostability, mechanical properties close to polypropylene in terms of stiffness and high barrier properties [6], comparable or even superior to PET [7]. On the other hand, in spite of the extent research done, PHB still presenting some shortcomings that handicap its industrial applicability. Among them, its still high production cost, low elongation-at-break, low toughness and tear resistance mainly due to its high crystallinity [8]. Moreover, PHB undergo an important embrittlement over time caused by secondary crystallization and physical ageing [9]. PHB also present a narrow 
processing window and is very sensitive to thermal degradation [10]. Altogether, these problems limit the application of PHB to packaging applications.

In the last decades, the development of natural fiber based polymer composites has become one of the research topics of greater tendency in the field of polymeric materials, and could be considered as an attractive approach to overcome some of the above-mentioned shortcomings of PHB [11-14]. Cellulosic fibers are cheap and abundant in nature and have, in general, high elastic modulus and relatively high thermal stability (at polymer processing temperatures). These characteristics make them appropriate for their use as reinforcing materials in polymeric matrices, enhancing the mechanical performance and reducing the final costs of the eventual composite [15-17] while decreasing the overall environmental impact of the product [18] Being cellulose the main component of plants, its use as reinforcing material allows the valorization of vegetal residues, thus promoting the circular economy while reducing the environmental impact of plastics. In this sense, the use of lignocellulosic residues from the agro-food industry as fillers for compostable polymer composite applications is an excellent circular approach to valorization of a residue, while enhancing the quality of the final compost.

Nevertheless, due to the natural origin of the cellulose fibers, the main features of the fibers (such as morphology, crystallinity, composition, purity, etc...) highly depend on the source [19] the extraction and purification method, the application of surface modifications or chemical treatments $[14,20]$. In this sense, the influence of the source of the fiber on the overall properties of a polymer composite requires to be assessed for each particular fiber.

In a previous work the valorization of lignocellulosic fibers obtained from almond shell (AS) and rice husk $(\mathrm{RH})$ as fillers in PHB based composites obtained by melt mixing has been assessed [21]. That work focused on the influence of fiber morphology, type and content on the mechanical, thermal, barrier properties, compostability and themoforming ability of the PHB/fiber composites. Although some differences were found, mainly related with the morphology of the fibers, both AS and RH have demonstrate their suitability as reinforcing materials for the studied matrix, and PHB/AS composites showed promising themoformabiliy. However, the barrier properties and thermal stability of the composites was considerably compromised.

Taking into account these preliminary results, some questions are still present. On the one hand, the effect of the use of untreated fibers on the PHB properties has not been evaluated in the previous study. On the other hand, an assessment of the effectiveness of a fiber treatment, in terms of whether the treatment of the fiber could yield to an improvement of the performance 
of the composite without a severe increase in the cost and environmental impact of the soobtained material, would be relevant. In particular, a study covering how the treatment influences the overall mechanical, thermal and crystallization behavior of the composites. And finally, what is the effect of the fibers incorporation on the embrittlement over time of PHB.

Aiming at answering these questions from an industrial point of view, in these work, $\mathrm{PHB} /$ fiber composites containing $10 \mathrm{phr}$ of AS or $\mathrm{RH}$ fibers without and with a combined $\mathrm{NaOH}+$ peracetic acid (PAA) treatment has been prepared by twin screw extrusion. A commercial cellulose grade (TC90) has been used as reference material. Peracetic acid treatment was selected because of it has higher selectivity in the removal of lignin and other non-cellulosic components than other methods such as chlorite/acetic acid while producing less severe impacts in cellulose structure, as reported by Kumar et al. [22]. In addition, according to Zhao et al. [23] a combined $\mathrm{NaOH}+$ PAA leads to high pulping yields and the fibers obtained possess superior mechanical properties and brightness compared to other usual pulping methods such as Kraft, while being a chlorinefree method is more environmentally friendly.

The influence of the untreated and treated fibers on morphology, thermal, crystallization, tensile properties, fracture toughness and dynamo mechanical behavior of the PHB/fiber composites has been studied. The effect of the fibers on the ageing and secondary crystallization of PHB has been also assessed.

\section{Experimental}

\subsection{Materials}

Commercial Poly(3-hydroxybutyrate) grade (P309) was purchased from Biomer ${ }^{\circledR}$ (Krailling, Germany) in pellet form. Micronized almond shell (AS) was kindly supplied by Unió Corporació Alimentària (Reus, Spain). Rice husk ( $\mathrm{RH}$ ) by-product from the rice production process was kindly provided by Herba Ingredients (Valencia, Spain). Purified alpha-cellulose fiber grade with an alpha-cellulose content $>99.5 \%$ (TC90) was purchased from CreaFill Fibers Corp. (US). Sodium hydroxide $(\mathrm{NaOH}, 98 \%)$, hydrogen peroxide $\left(\mathrm{H}_{2} \mathrm{O}_{2}, 30 \%\right)$, glacial acetic acid $\left(\mathrm{CH}_{3} \mathrm{COOH}, 99 \%\right)$ and sulphuric acid $\left(\mathrm{H}_{2} \mathrm{SO}_{4}, 98 \%\right)$ were purchased from Sigma Aldrich. 


\subsection{Fiber treatment}

Almond Shell (AS) and Rice Husk (RH) fibers were subjected to a two-stage purification treatment in order to remove the major part of impurities and non-cellulosic components such as waxes, lignin and hemicelluloses.

Prior to purification treatment micronized Almond Shell was sieved through a $140 \mu \mathrm{m}$ mesh and native rice husk was grinded in a mechanical knife mill and then sieved in $140 \mu \mathrm{m}$ mesh. Grinded and sieved AS and RH powders were subjected to the two-stage purification treatment. The first stage consisted in an alkaline attack with $\mathrm{NaOH}$. The fibers were soaked in $5 \%$ (wt/v) $\mathrm{NaOH}$ solution for $2 \mathrm{~h}$ at $80^{\circ} \mathrm{C}$ under vigorous stirring maintaining a fibre:liquid ratio of 1:20. This treatment was applied twice. The second stage consisted in an oxidative attack with peracetic acid (PAA). Alkaline pretreated fibers were soaked into peracetic acid with a fiber:liquid ratio of $1: 20$ under vigorous stirring at $80^{\circ} \mathrm{C}$ for $4 \mathrm{~h}$ (until whitening of suspension was visually detected). The peracetic acid was prepared by the mixing of $30 \%(\mathrm{v} / \mathrm{v})$ hydrogen peroxide and acetic acid in the reaction medium with a volume ratio of $3: 1$ at room temperature. $1 \%(w / w)$ of sulfuric acid was added as catalyzer to ensure a chemical shift in the direction of the products. This procedure was adapted from literature $[23,24]$. After each stage the fibers were filtered and washed repeatedly in distilled water until neutral $\mathrm{pH}$ was reached. The purified powder was dried at $60{ }^{\circ} \mathrm{C}$ for at least 24 hours and grinded again and sieved through a $140 \mu \mathrm{m}$ mesh.

Untreated Almond Shell and Rice Husk fibers were named as U_AS and U_RH, and treated ones as T_AS and T_RH, respectively.

\subsection{Samples preparation}

Before extrusion, the PHB used in this study was dried according to the manufacturer instructions in a Piovan dehumidifying drier and the commercial cellulose (TC90) and the untreated (U_AS, U_RH) and treated (T_AS, T_RH) fibers were dried at $100^{\circ} \mathrm{C}$ in oven for at least 2h. Composites containing $10 \mathrm{phr}$ (referred to $100 \%$ wt. unit PHB) fiber loading were prepared in a twin-screw co-rotating extruder from DUPRA SL (Castalla, Spain) with L/D ratio of 24 and a diameter of $2.5 \mathrm{~cm}$, with a temperature profile of $165 / 170 / 175 / 180 \mathrm{OC}$ (from the hopper to the extruder die) at a speed of $40 \mathrm{rpm}$. The PHB pellets and the fibers were manually dry-mixed in zip-bags before extrusion and fed to the extruder hopper. The extruded material was pelletized and dried at in a Piovan. Compression moulded samples were obtained in a hot-plate press (Carver Inc. E 43201) at $180^{\circ} \mathrm{C}$. Bars of $50 \times 12.5 \times 3.5 \mathrm{~mm}$ for dynamo-mechanical analysis tests, 
films of 0.4 nominal thickness for uniaxial mechanical tests and plates of $2.4 \mathrm{~mm}$ nominal thickness for Linear Elastic Fracture Mechanics (LEFM) tests were obtained. The different formulations studied were named as PHB/X, were $X$ corresponds to the fiber type: TC90, U_AS, U_RH, T_AS and T_RH.

\subsection{Characterization}

The morphology of the untreated and treated AS and RH fibers, the commercial cellulose (TC90) and the PHB/fiber composites was examined by scanning electron microscopy (SEM) using a high-resolution field-emission JEOL 7001F microscope. The aspect ratio and the average particle size of the different fibers were estimated using the image analysis software $\mathrm{Fiji}^{\circledR}$ (the number of particles measured was never below 250). Composite films were cryofractured after immersion in liquid nitrogen to avoid plastic deformation. The fibers and composites were coated by sputtering with a thin layer of platinum for the SEM analysis. The elemental analysis of $\mathrm{RH}$ fibers was conducted by energy dispersion $\mathrm{X}$ ray microanalysis (EDX).

The crystallinity of the untreated and treated AS and RH fibers and the TC90 was assessed by Wide angle X-ray scattering (WAXS) using a Bruker AXS D4 Endeavor diffractometer. Radial scans of intensity versus scattering angle $(2 \theta)$ were recorded at room temperature in the range of 2 to $40^{\circ}(2 \theta)$ (step size $=0.02^{\circ}(2 \theta)$, scanning rate $=4 \mathrm{~s} /$ step) with filtered CuKa radiation $(\lambda=1.54$ A), an operating voltage of $40 \mathrm{kV}$, and a filament current of $40 \mathrm{~mA}$. The crystallinity was evaluated according to Seagal et al. [25] method, where the crystallinity index $\mathrm{Ci}$ can be determined with the following equation (1):

$C_{i}(\%)=\frac{I_{002}-I_{a m}}{I_{002}} \times 100$

where $\mathrm{I}_{002}$ is the maximum intensity of the (002) lattice diffraction peak of cellulose located at a diffraction angle of around $22 \circ(2 \theta)$ and $\mathrm{l}_{\mathrm{am}}$ is the intensity scattered by the amorphous phase of the sample measured at around $18 \circ(2 \theta)$.

Fourier infrared (FT-IR) spectra of the untreated and treated AS and RH fibers and the TC90 were recorded by a Jasco FT/IR-6200 equipped with an attenuated total reflection (ATR) accessory in the range of $400-4000 \mathrm{~cm}^{-1}$ in transmission mode.

Thermogravimetric analysis (TGA) of the untreated and treated AS and RH fibers, the TC90, as well as the neat PHB and its composites, was performed with a TG-STDA Mettler Toledo model TGA/STDA851e/LF/1600 analyzer. The samples with an initial mass of typically about $15 \mathrm{mg}$ were 
heated from 50 to $600^{\circ} \mathrm{C}$ at a heating rate of $10^{\circ} \mathrm{C} / \mathrm{min}$ under nitrogen flow. The thermal stability of both the fibers and the $\mathrm{PHB} /$ fiber composites was evaluated and the residue at $600^{\circ} \mathrm{C}$ was determined. For the composites, the initial decomposition temperature $\left(T_{5 \%}\right.$, temperature at $5 \%$ weight loss) and the maximum decomposition rate temperature $\left(T_{d}\right)$ were determined from the weight loss curve and the maximum value of weight loss derivative respectively.

The mechanical characterization of neat PHB and the composites was performed by tensile tests according to the ASTM D638 standard, using dumbbell $400 \mu \mathrm{m}$-thick samples (Type IV) die-cut from the hot pressed films. Tensile tests were conducted in a universal testing machine (Shimatzu AGS-X 500N) at room temperature with a cross-head speed of $10 \mathrm{~mm} / \mathrm{min}$. The samples were tested immediately after be processed ( 0 days) and after 15 days to explore the effect of ageing and secondary crystallization on their mechanical performance [9]. All the samples were stored in a vacuum desiccator at ambient temperature until be tested.

Linear Elastic Fracture Mechanic (LEFM) was applied using single edge notched bend (SENB) specimens, as depicted in Fig. 1. The samples were prepared by cutting the hot-pressed plates (nominal dimensions: $2.4 \times 12.7 \times 44 \mathrm{~mm}$ ). Notches were produced centrally on the narrowest side of the prismatic bars, using a $450 \mathrm{~V}$ notch-broaching tool. Prior to testing, the notches were sharpened with a single cut from a razor blade (razor pushing) in order to get an initial sharp crack, as indicated in the European Structural and Integrity Society (ESIS) protocols for KIC determination [26]. The depth of such sharpening, $\Delta a$, was measured using a binocular microscope on each fractured specimen, in order to determine the real value of the crack $\left(a_{0}+\right.$ $\Delta$ a). $\Delta$ a values were around $0.2 \mathrm{~mm}$ in all specimens. The tests were performed using a universal testing machine Shimatzu AGS-X equipped with a $5 \mathrm{kN}$ load cell. The crosshead speed of the test was $10 \mathrm{~mm} / \mathrm{min}$. The notch depth (i.e. initial crack length), a of SENB specimens was set to $7 \mathrm{~mm}$ and the tests were conducted at room temperature. The fracture toughness $\left(K_{\mathrm{IC}}\right)$ was calculated by the ESIS protocol [26].

$K_{I C}=f \frac{P_{C}}{B W^{1 / 2}}$

where $\mathrm{P}_{\mathrm{C}}$ is the maximum load point. $\mathrm{B}$ and $\mathrm{W}$ are thickness and width of the specimens. The geometrical correction factor, $f$, a function of a/W where $a$ is the initial crack length (i.e. $a_{0}+\Delta a$ ), was obtained from the ESIS protocol [26]. 


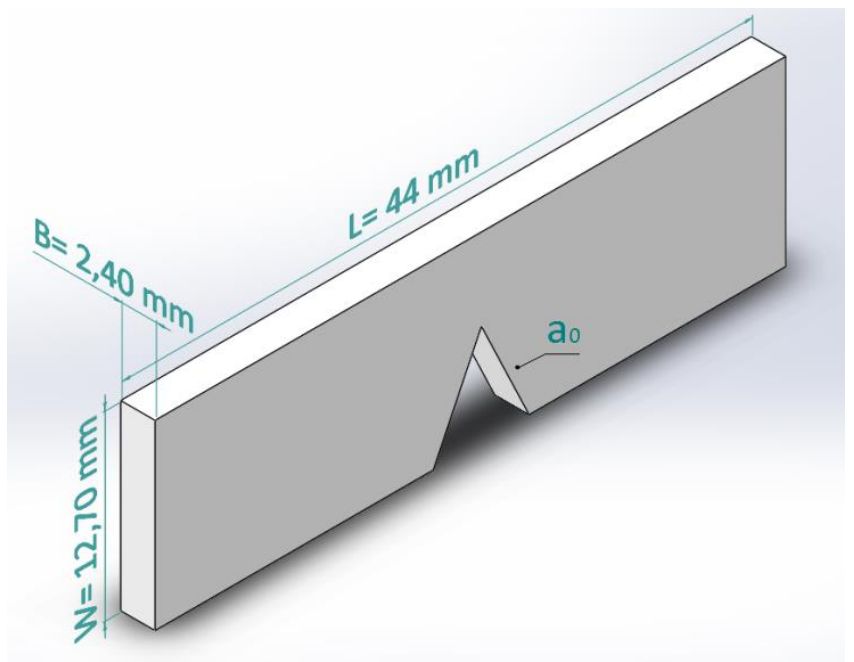

Figure 1. Scheme of SENB specimens

Dynamic mechanical analysis (DMA) experiments were conducted on hot pressed sample platelets $(55 \times 12.5 \times 3.5 \mathrm{~mm})$ in an AR G2 oscillatory rheometer (TA Instruments, New Castle, DE) equipped with a clamp system for solid samples (torsion mode). Samples were heated from $-20^{\circ} \mathrm{C}$ to melting temperature with a heating rate of $2{ }^{\circ} \mathrm{C} / \mathrm{min}$ at a constant frequency of $1 \mathrm{~Hz}$. The maximum deformation $(\gamma)$ was set to $0.1 \%$.

Differential scanning calorimetry (DSC) experiments were conducted on a DSC2 (Mettler Toledo) with an intracooler (Julabo FT900) calibrated with an Indium standard before use. The samples weighing typically $6 \mathrm{mg}$ were first heated from $-20^{\circ} \mathrm{C}$ to $200^{\circ} \mathrm{C}$ at $10^{\circ} \mathrm{C} / \mathrm{min}$ and kept for $5 \mathrm{~min}$ to erase thermal history, followed by cooling to $-20^{\circ} \mathrm{C}$ and heating to $200^{\circ} \mathrm{C}$ at $10 \circ \mathrm{C} / \mathrm{min}$. The samples were tested at 0 days and after 100 days of ageing at room temperature. Melting temperature $(\mathrm{Tm})$ and enthalpy $(\Delta \mathrm{Hm})$ were calculated from the first and second heating scans and crystallization temperature $(\mathrm{Tc})$ and enthalpy $(\Delta \mathrm{Hc})$ from the cooling scan. The crystallinity $(\mathrm{Xc})$ of the PHB phase of the composites was determined by applying the following expression [27]:

$X_{c}(\%)=\frac{\Delta H_{m}}{w \cdot \Delta H_{m}^{0}} \times 100$

where $\Delta \mathrm{Hm}(\mathrm{J} / \mathrm{g})$ is the melting enthalpy of the polymer matrix, $\Delta \mathrm{H} \cong \mathrm{m}$ is the melting enthalpy of $100 \%$ crystalline PHB (perfect crystal) $(146 \mathrm{~J} / \mathrm{g}$ ) [9] and $\mathrm{w}$ is the polymer weight fraction of PHB in the blend. 


\section{Results and discussion}

\subsection{Fiber characterization}

SEM micrographs of the untreated and treated AS and $\mathrm{RH}$ fibers and commercial cellulose, the estimated aspect ratio and average particle size of the different fibers and the EDX microanalyses of RH fibers are shown in Figure 2.

Untreated Almond Shell (U_AS) powder was composed by irregular particles and aggregates with an average particle size of about $45 \mu \mathrm{m}$ and an estimated aspect ratio of around 2 . The particles present a porous surface with the presence of small pinholes. The combined $\mathrm{NaOH}$ and PAA treatment didn't significantly change the morphology of AS fibers. Only a slight increase in the surface roughness can be observed in T_AS particles with respect to U_AS; however, the average size is of about $42 \mu \mathrm{m}$ and the aspect ratio is of c.a.2. Hence, the treatment has no apparent effect on the morphology of the fibers.

The U_RH powder is formed by particles of different morphologies (rod-shaped, junks and fibers) whose particle sizes vary from a few microns up to $300 \mu \mathrm{m}$ in length. With close examination a smooth surface of the particles can be observed, probably related with the presence of waxes as it will be further discussed. The EDX microanalysis reveals the presence of silica with an estimated content around $14 \%$, this value is in accordance with the ones reported in literature for this type of fibers [28]. In this case, the combined $\mathrm{NaOH}$ and PAA treatment had a big impact on the morphology of $\mathrm{RH}$ fibers. After treatment the particles present fibrillary morphology with more homogeneous particle size distribution with an average particle size ranging from 150 to $200 \mu \mathrm{m}$ in length and high aspect ratio, estimated at about 18 . The particles surface presents a rough topography. This finding suggests the removal of waxes and other noncellulosic components by the treatment. The EDX microanalysis didn't reveal the presence of silica, evidencing the effectiveness of the treatment in removing this component.

The commercial cellulose used in this study as a reference material has a fibrillary morphology. The fibers present varying lengths up to $200 \mu \mathrm{m}$. In all cases, the diameter is contained within the 10-20 $\mu \mathrm{m}$ range, thus rendering an average aspect ratio of about 10 . 


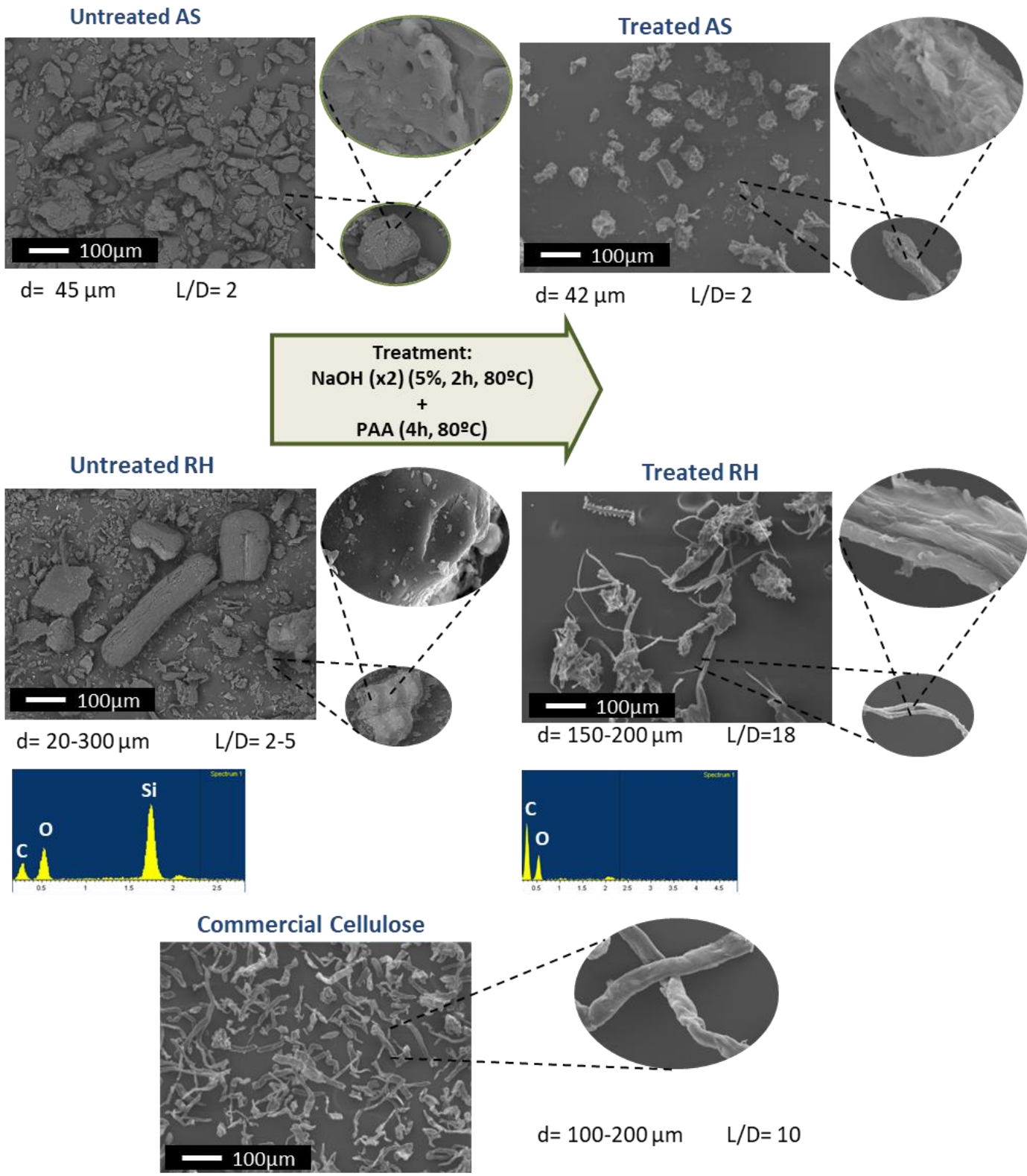

Figure 2. SEM micrographs of the untreated and treated RH and AS fibers, the commercial cellulose (TC90), and EDX microanalysis of RH fibers

The crystallinity index $\left(C_{i}\right)$ of the U_AS, U_RH, T_AS, T_RH and TC90 fibers was determined by WAXS according to Seagal et al. [25] (equation 1). WAXS patterns of the studied fibers are shown in Figure 3. 


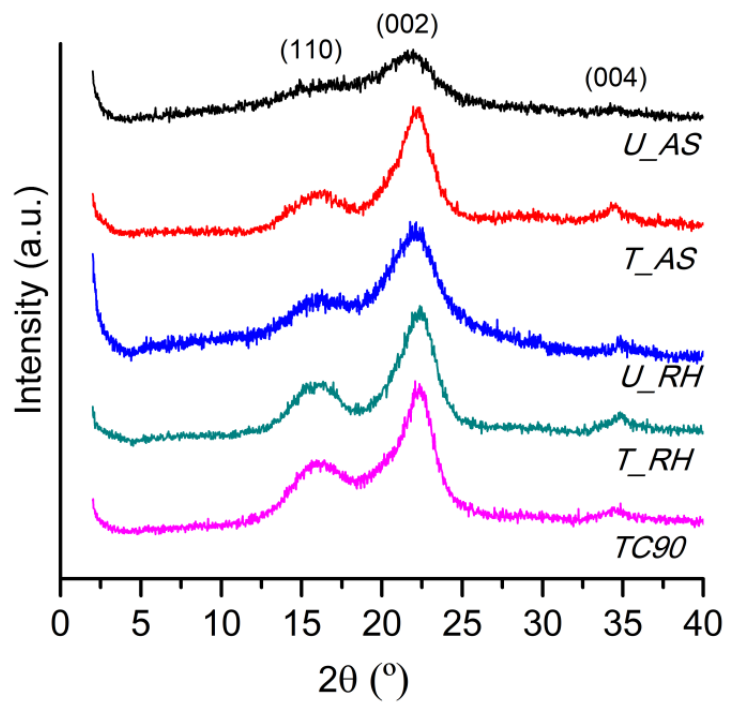

Figure 3. WAXS patterns of TC90 and untreated and treated AS and RH fibers

All the fibers present a characteristic X-ray diffraction pattern of a semicrystalline material with an amorphous broad hump and different crystalline peaks. Three peaks located at $16 \circ, 22^{\circ}$ and 34 - can be observed in all cases, which are characteristics of the (110), (002) and (004) reflections of type I cellulose lattice $[29,30]$. When assessing the crystallinity of the untreated AS and $\mathrm{RH}$, the values of crystalline index $\left(C_{i}\right)$ (according to eq. (1)) of 40 and $48 \%$, respectively. After treatment their crystallinity indexes were increased to 69 and $70 \%$. These values are comparable to that corresponding to commercial cellulose, TC90, that presents a $C_{i}$ of $63 \%$ and are coherent with those reported in literature for these types of fibers [31, 32]. The increase in crystallinity after treatment is indicative of the elimination of amorphous components present in the fibers (mainly lignin and hemicelluloses) [30, 33].

FTIR was employed in this work in order to verify the effectiveness of the chemical treatment in removing the non-cellulosic components of fibers, such as lignin, hemicelluloses, pectin or waxes. The FTIR spectra of untreated and treated AS and RH fibers and the commercial cellulose (TC90), as reference, are represented in Figure 4. 


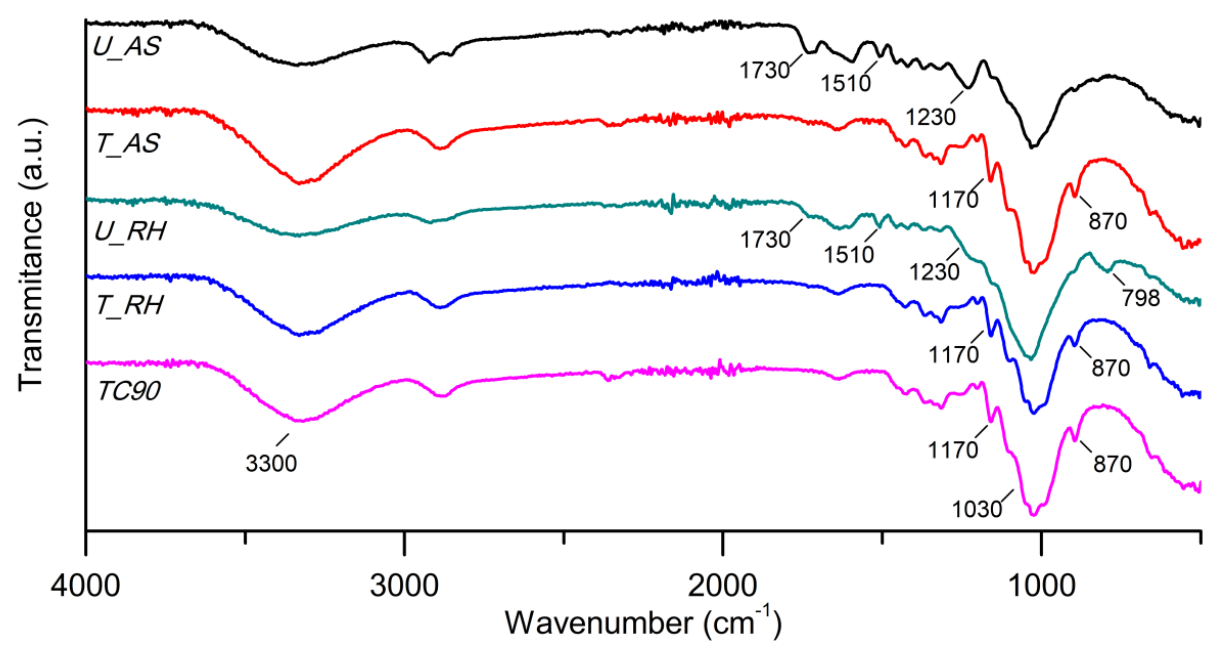

Figure 4. FTIR spectrograms of TC90 and untreated and treated AS and RH fibers

Untreated AS and RH fibers present the characteristic bands of lignin, hemicelluloses, waxes and pectin. The band at $1730 \mathrm{~cm}-1$ is ascribed to either acetyl and carbonyl groups from carboxylic ester linkages in hemicelluloses and lignin [34,35], or to pectin, wax and natural fats [36, 37], the band at $1510 \mathrm{~cm}-1$ is due to the $C=C$ stretching of the aromatic rings present in the lignin structure $[38,39]$, and the band in the $1200-1250 \mathrm{~cm}-1$ spectral region is ascribed to $-\mathrm{C}-\mathrm{O}$ stretching vibration of the acetyl groups in lignin and hemicelluloses [35, 39]. All this bands are not detected in the spectra corresponding to treated AS and RH fibers and commercial cellulose, thus indicating the successfully removal of these components through the treatment. The band at $798 \mathrm{~cm}^{-1}$ present in the U_RH corresponding to the silica vibrations [34] also disappears in T_RH spectrum confirming the results obtained by EDX microanalysis, as it has been discussed in SEM results. Additionally, the intensity of the broad band around $3300 \mathrm{~cm}^{-1}$ is increased in T_AS and T_RH spectra with respect to untreated fibers and it start to appear a shoulder on this band. According to Ndazi et al. [34] and Mariano et al.[24] the increased intensity of this band and the shoulder are indicative of the presence of more free $-\mathrm{OH}$ reactive groups on the fibers surface. Also, the characteristic bands of vibrational C-O-C, C-O and C-H strain of cellulose [35, 39] at $1170 \mathrm{~cm}^{-1}, 1030 \mathrm{~cm}^{-1}$ and $896 \mathrm{~cm}^{-1}$ show better resolution and higher intensity in spectra corresponding to treated and commercial cellulose fibers than in the spectra corresponding to untreated ones, also confirming the purification of the fibers by the treatment.

The thermal stability of the untreated and treated AS and RH fibers and the TC90 was studied by TGA. The weight loss and first derivative (DTG) curves are shown in Figure 5. 


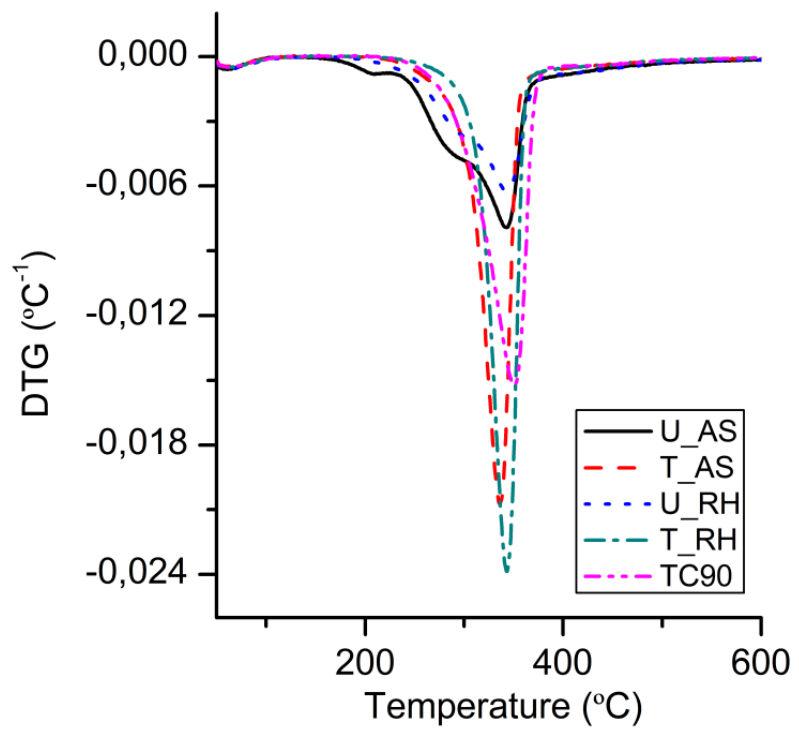

Figure 5. Weight loss (a) and DTG (b) curves corresponding to TC90 and untreated and treated AS and RH fibers

As shown in Figure 5 the thermal degradation of the untreated fibers takes place in a broad range of temperatures with different weight loss steps related to the thermal degradation of its main components (hemicelluloses, cellulose and lignin). The decomposition of hemicelluloses primarily occurs between $220-315^{\circ} \mathrm{C}$. Cellulose decomposes at higher temperatures (around $345^{\circ} \mathrm{C}$ ), whilst lignin decomposition happens slowly over the whole temperature range studied $[30,40]$. In addition, U_AS and U_RH present a residue at $600{ }^{\circ} \mathrm{C}$ of 26 and $41 \%$, respectively. The higher residues with respect to treated fibers are related with their high content of lignin and, in case of $\mathrm{RH}$, also by the silica present in its composition. On the other hand, the thermal 
degradation of TC90 and the treated fibers takes place in a single step with the highest weight loss rate at, approximately, $345 \circ \mathrm{C}$ corresponding to cellulose degradation and a residue of $12 \%$, confirming the successfully removal of the non-cellulosic components through the treatment. In addition, after treatment, the onset degradation temperature of the AS and RH fibers was displaced about $40^{\circ} \mathrm{C}$ to higher temperatures thus indicating that their thermal stability were improved.

In a previous work we used a combined $\mathrm{NaOH}+\mathrm{H}_{2} \mathrm{O}_{2}$ purification treatment for $\mathrm{AS}$ and $\mathrm{RH}$ fibers [21]. Attending to the results obtained by means of the treatment applied in here (combined $\mathrm{NaOH}+\mathrm{PAA}$ ), it seems to be more efficient in removing the non cellulosic components, thus yielding to fibers with higher purity grade and relative crystallinity indexes.

\subsection{Composites characterization}

To evaluate the particle distribution and the fiber/matrix interactions, the morphology of the cryofractured surfaces of PHB/fiber composites was studied by SEM. The micrographs of the composites with TC90, U_AS, T_AS, U_RH and T_RH fibers are presented in figure 6 .

In general, the composites prepared with the studied fibers (U_AS, T_AS, U_RH and T_RH) present a particle distribution similar to that corresponding to the commercial cellulose (TC90). In all cases the fibers appear individualized and homogeneously distributed within the polymeric matrix indicating that an effective blending was achieved. However, some differences can be detected among the different fibers regarding to the fiber-matrix interactions. For the untreated fibers, pull-out effect (marked with an arrow) can be observed, whilst this is not evident in the composites prepared with the treated fibers and the TC90. This phenomenon could be related to the presence of waxes and impurities on the untreated fiber surface, together with a more limited $-\mathrm{OH}$ reactive groups exposed. These waxes and other non-cellulosic components could form a weak layer that hinders the fiber/matrix interaction. In the micrograph corresponding to PHB/U_RH it can be observed a fiber with a very smooth surface as a result of the presence of 


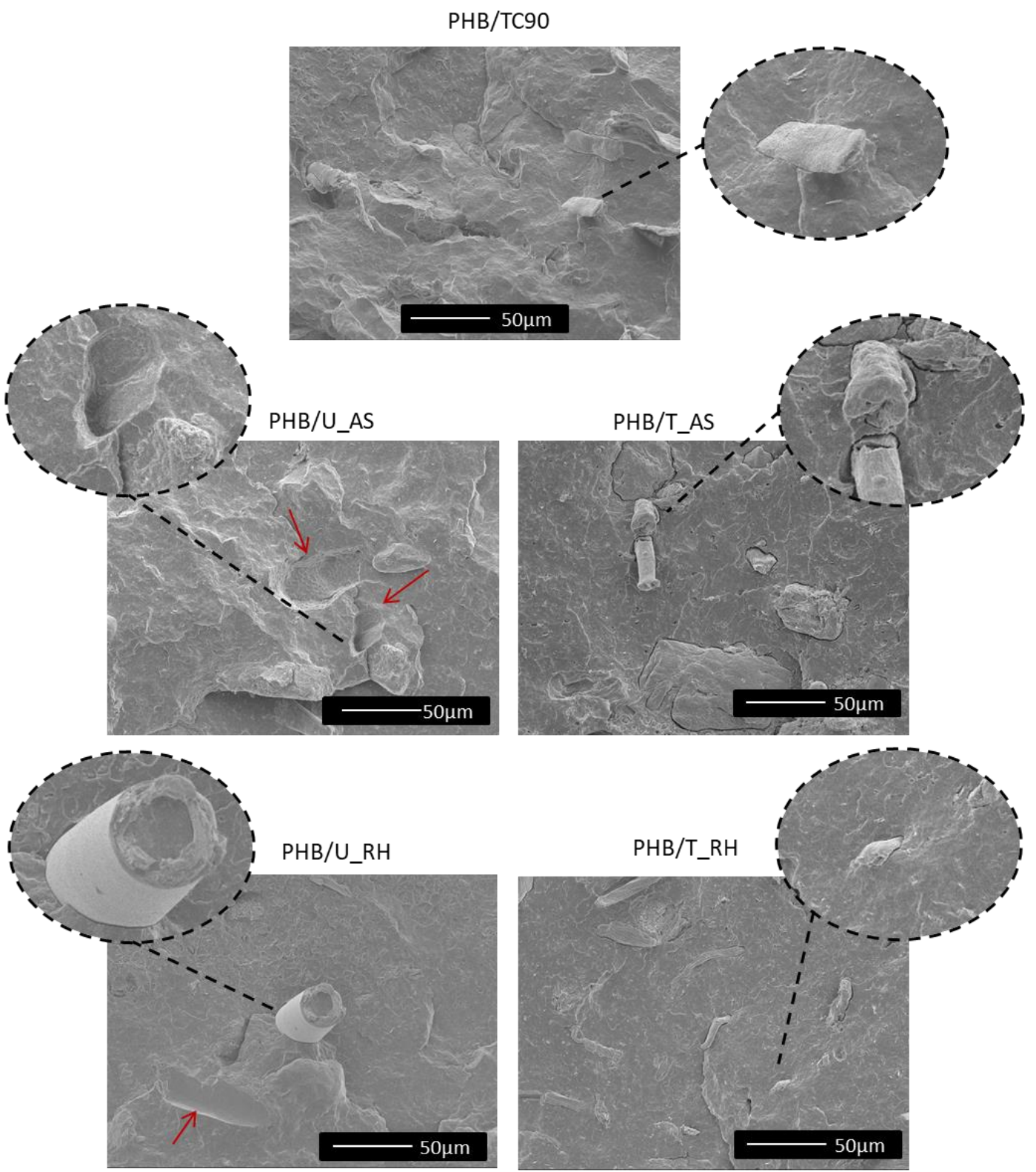

Figure 6. SEM micrographs of PHB/TC90, PHB/U_AS, PHB/T_AS, PHB/U_RH and PHB/T_RH composites

these non-cellulosic components (probably waxes). In case of the composites containing the T_AS, T_RH and TC90 the presence of some broken fibers that seem to be well embedded into the PHB matrix suggesting certain enhanced fiber-matrix interaction with respect to untreated fibers. However, some small gaps between the fibers and the polymeric matrix can be also detected, especially in PHB/T_AS composites. These gaps may have been induced during the specimen preparation by means of immersion in liquid nitrogen and subsequent brittle fracture.

The mechanical properties of the composites were evaluated by uniaxial tensile tests up to break. The effect of the intrinsic embrittlement of PHB with time due to secondary crystallization and physical ageing [9] on the mechanical performance of PHB/composites was also evaluated. 
Tensile modulus of elasticity, tensile strength at yield and elongation at break of the composites
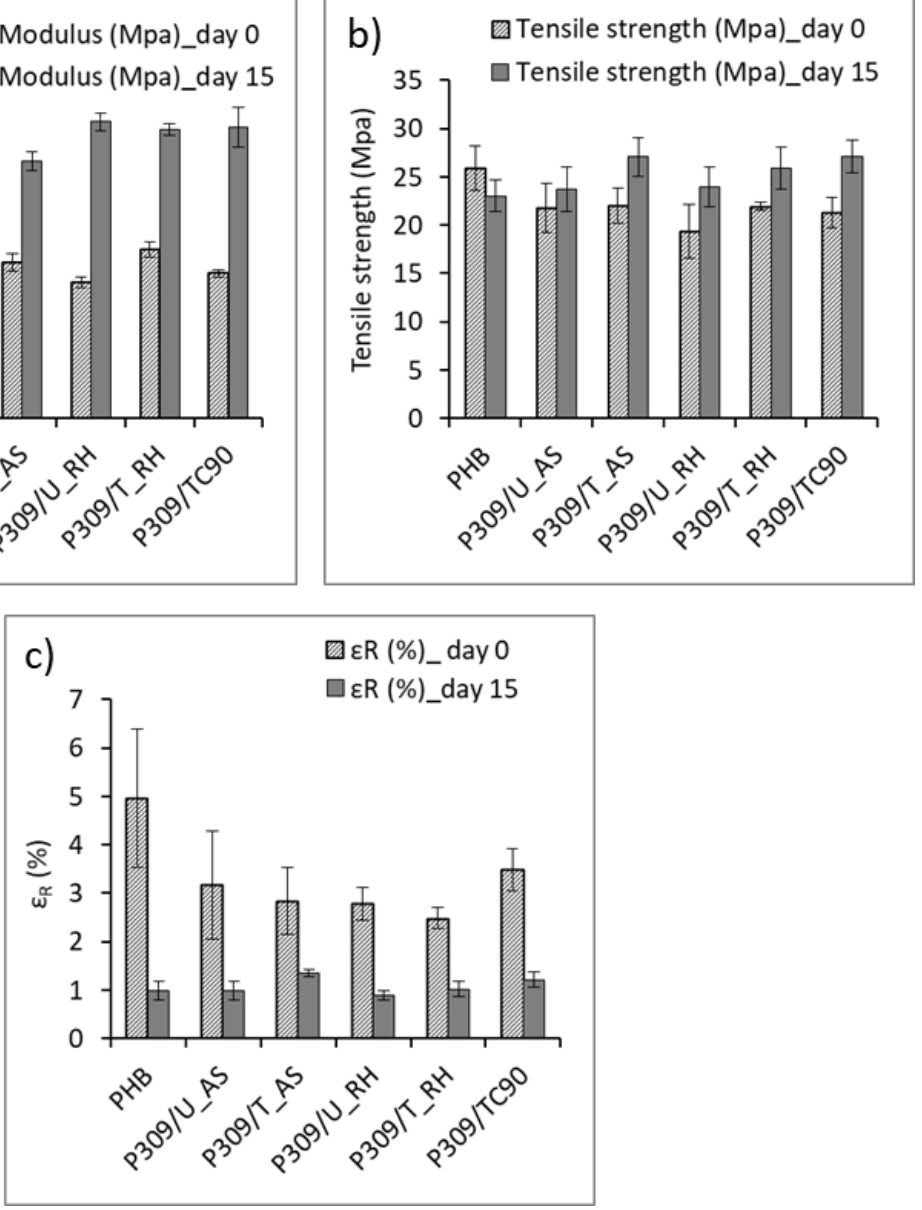

Figure 7. Tensile modulus (a), Tensile strength (b) and elongation at break (c) of neat PHB and the composites.

The mechanical behavior of neat PHB and PHB/fiber composites is not the same at 0 days and after 15 days of ageing. At 0 days the mechanical behavior is dominated by the fiber/matrix interactions whilst at 15 days the behavior is more dependent on the secondary crystallization and physical ageing.

As shown in Figure 6 at 0 days PHB presents a tensile modulus of $1400 \mathrm{MPa}$, a tensile strength of $26 \mathrm{MPa}$ and an elongation at break of $5 \%$. The incorporation of the fibers leads in all cases to clear improvement of the elastic modulus due as a result of their reinforcing nature; while a slight reduction of tensile strength and elongation at break can be also detected, as is typical in short fiber reinforced composites with a brittle polymer matrix. At certain level of stress, the fibers act as flaws (i.e. stress concentrators) leading to a premature failure and, consequently, a reduction in tensile strength and elongation at break [41]. 
Most noticeable increase in tensile modulus is found for the treated fibers. In particular, the tensile modulus of PHB/T_RH composites was increased of about $40 \%$ with respect to neat PHB and $17 \%$ compared to the commercial cellulose. The higher reinforcing effect of treated fibers with respect to untreated ones could be attributed to the increased crystallinity and purity of the fibers, together with a higher presence of hydroxyl groups on the surface leading to a better interaction by hydrogen bonds with the polymer carbonyl groups [42-44].

After 15 days of ageing at room conditions, a clear embrittlement of the PHB matrix is evidenced. This behavior is attributed in literature to a secondary crystallization and physical ageing (reduction of the mobility of amorphous phase and constriction of rigid amorphous regions) [45, 46]. In neat PHB ageing produces an increase in modulus and a decrease in elongation at break (Fig. 7). For the composites the increase in tensile modulus is also observed, while the tensile strength and the elongation at break are slightly superior to those corresponding to neat PHB.

The fiber treatment does not seem to have any influence on the elastic modulus of the composites after ageing. Nevertheless the tensile strength is slightly higher for the composites prepared with the treated fibers with respect to the untreated ones. This could be due to a less fiber/matrix detachment owing to a better fiber adhesion.. In addition, the presence of impurities and waxes on the untreated fiber surfaces could promote the fiber/matrix detachment by a weak layer mechanism as it has been discussed in SEM results, as pull-outs have been detected (Fig 6). In any case, all the compositions present fragile behavior.

\section{$\underline{L E F M}$}

To assess the influence of the fiber type on the PHB fracture behavior three point bending tests at slow speed $(10 \mathrm{~mm} / \mathrm{min})$ were performed and the results were analyzed following the fracture mechanics approach. The behavior was in all cases sufficiently linear to allow the application of the linear elastic fracture mechanics (LEFM) to characterize the fracture toughness $\left(K_{I C}\right)$ according with ESIS protocol [26]. The results are summarized in Figure 8: a representative force-displacement curve are represented in Figure 8a, the $\mathrm{K}_{\mathrm{Ic}}$ values of the materials are shown in Figure $8 \mathrm{~b}$ and representative photographs and SEM micrographs of the fractured specimens are depicted in Figure 8c. 

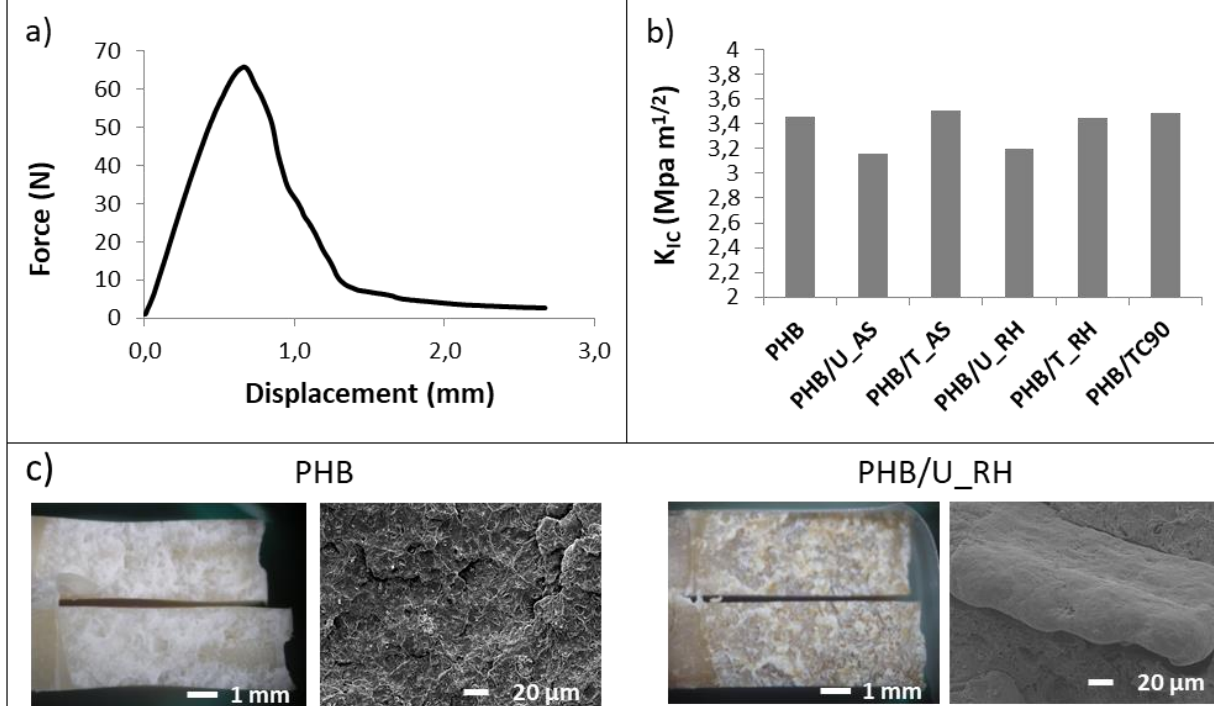

PHB

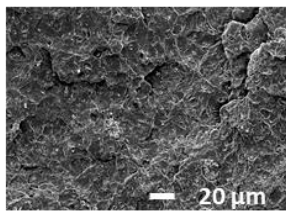

$\mathrm{PHB} / \mathrm{U}$ AS

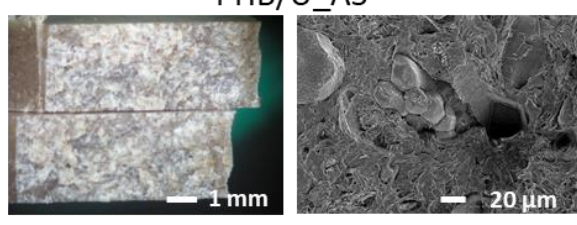

PHB/T_AS
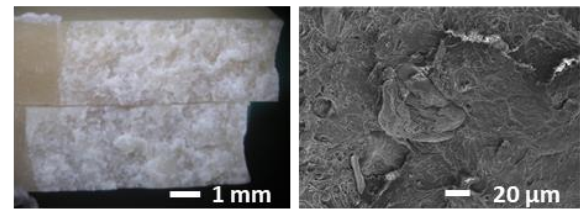

PHB/U_RH

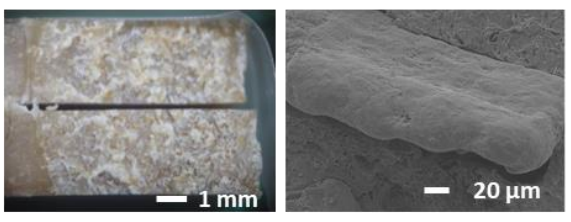

$\mathrm{PHB} / \mathrm{T}_{-} \mathrm{RH}$
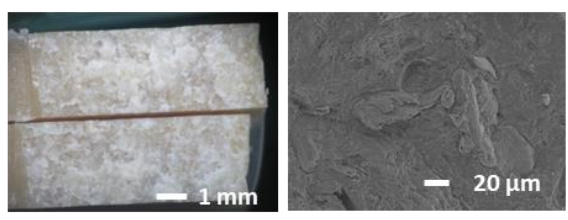

$\mathrm{PHB} / \mathrm{TC90}$
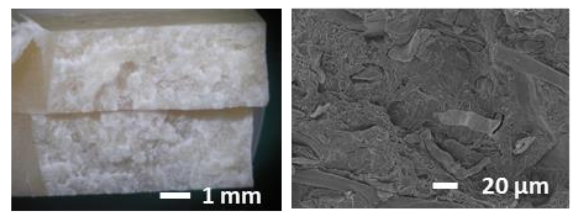

Figure 8. LEFM results: representative force-displacement curve (a), KIC values of neat PHB and the composites (b), and representative SEM micrographs of the fractured specimens (c)

According to the results presented in Figure $8 \mathrm{~b}$, the composites containing the treated fibers and the commercial cellulose (PHB/T_AS, PHB/T_RH and PHB/TC90) present $\mathrm{K}_{\mathrm{IC}}$ values similar to neat PHB. A slight decrease in fracture toughness is observed for the composites containing the untreated fibers (PHB/U_AS and PHB/U_RH). In any case, the differences in $K_{\mathrm{IC}}$ values are below $10 \%$.

As shown in Figure 8c, the matrix presents a fracture morphology with microcavities and unstable crack propagation and even deviation of the transverse plane to the application of force which implies high concentration of elastic energy attributable to a high crystallinity (see DSC Table 1) and little fraction of tie molecules. Nevertheless, the fracture surface also shows some small crests that are indicative of certain localized plastic deformation of the matrix that is coherent at temperatures above Tg. On the one hand, the introduction of cellulose should suppose an increase in rigidity and toughness, but, on the other hand, the fibers act as crack initiators or stress concentrators. For untreated fibers the reinforcing effect is lower and the stress concentration is higher (due to minor fiber /matrix interaction). As shown in Figure 8c, in 
PHB/U_AS and PHB/U_RH the detachment of the fibers is evident supporting the hypothesis of a "weak layer mechanism" failure caused by the presence of impurities and waxes on the fiber surface.

\section{$\underline{D M A}$}

In addition to mechanical and fracture toughness characterization dynamic mechanical analysis (DMA) was performed in order to assess the effect of temperature on the mechanical behavior of the PHB and the composites. The storage modulus $\left(\mathrm{G}^{\prime}\right)$ and the Tan delta (Tan $\delta$ ) curves as a function of temperature are shown in Figures $9 a$ and $9 b$, respectively.

As it was expected, the $\mathrm{G}^{\prime}$ of PHB, which is a measure of the stiffness of a viscoelastic material, decreases as the temperature increases due to the softening of the sample at higher temperatures (Fig.9a). A slight increase in $\mathrm{G}^{\prime}$ is observed in filled compositions that is related with the increased rigidity of the samples because of the reinforcing effect of the fibers $[43,47]$ Nevertheless, the differences in $\mathrm{G}^{\prime}$ among the different compositions are quite small.

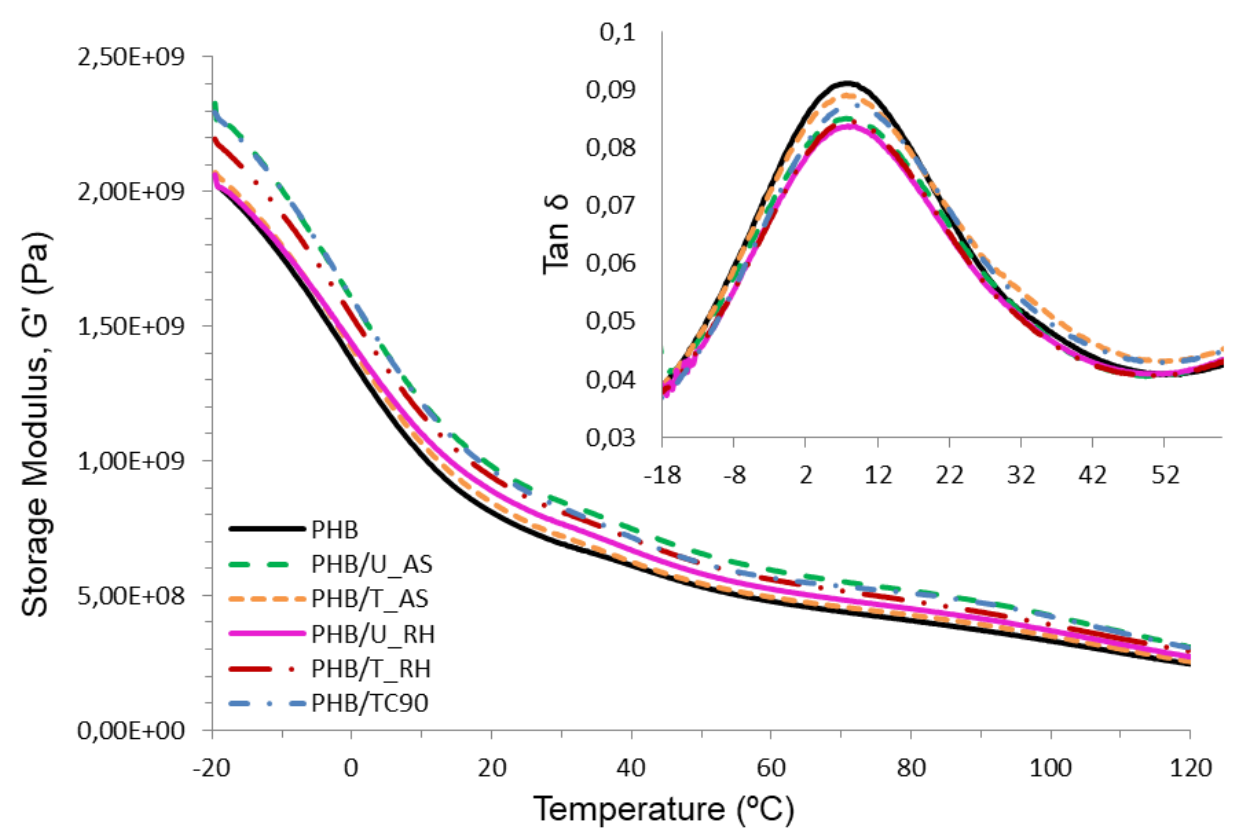

Figure 9. Storage modulus ( $\left.G^{\prime}\right)$ and Tan $\delta$ (inset) evolution with temperature of neat PHB and the composites

Tan $\delta$ represents the ratio of the viscous and elastic components of the modulus and is a measure of the energy dissipated as heat during the dynamic test [48]. The Tan $\delta$ curve presents a single event before melting for the studied range, being this event the $\alpha$ transition, generally 
attributed to the glass transition $\left(T_{g}\right)$ in semicrystalline polymers [49]. The $T_{g}$ value for neat PHB

Table 1. DSC parameters of neat PHB and the composites

\begin{tabular}{|c|c|c|c|c|c|c|}
\hline & \multicolumn{6}{|c|}{ 1st heating scan } \\
\hline & \multicolumn{3}{|c|}{0 days } & \multicolumn{3}{|c|}{100 days } \\
\hline & $T_{m}(\circ C)$ & $\Delta H_{m}(\mathrm{~J} / \mathrm{g})$ & $X_{c}(\%)$ & $T_{m}(\stackrel{\circ}{ })$ & $\Delta H_{m}(\mathrm{~J} / \mathrm{g})$ & $X_{c}(\%)$ \\
\hline PHB & 175,1 & 72,0 & 49,3 & 169,6 & 85,8 & 58,7 \\
\hline PHB/U_AS & 174,0 & 71,9 & 54,2 & 171,8 & 74,0 & 55,8 \\
\hline PHB/T_AS & 171,6 & 60,0 & 45,2 & 172,1 & 72,0 & 54,2 \\
\hline PHB/U_RH & 172,1 & 70,8 & 53,3 & 172,1 & 73,5 & 55,4 \\
\hline PHB/T_RH & 175,0 & 68,5 & 51,6 & 172,8 & 73,4 & 55,3 \\
\hline \multirow[t]{3}{*}{ PHB/TC90 } & 172,8 & 73,7 & 55,5 & 172,7 & 73,0 & 55,0 \\
\hline & \multicolumn{2}{|c|}{ cooling scan } & \multicolumn{4}{|c|}{ 2nd heating scan } \\
\hline & $\mathrm{T}_{\mathrm{c}}(\stackrel{\circ}{\mathrm{C}})$ & $\Delta \mathrm{H}_{\mathrm{c}}(\mathrm{J} / \mathrm{g})$ & & $T_{m}(\circ C)$ & $\Delta \mathrm{H}_{\mathrm{m}}(\mathrm{J} / \mathrm{g})$ & $X_{c}(\%)$ \\
\hline PHB & 117,2 & 90,6 & & 169,6 & 93,9 & 64,3 \\
\hline PHB/U_AS & 118,2 & 85,0 & & 168,3 & 86,3 & 65,0 \\
\hline PHB/T_AS & 117,7 & 82,6 & & 169,7 & 86,3 & 65,0 \\
\hline PHB/U_RH & 115,9 & 81,8 & & 168,5 & 85,0 & 64,1 \\
\hline PHB/T_RH & 116,8 & 83,7 & & 169,9 & 86,3 & 65,0 \\
\hline PHB/TC90 & 117,1 & 82,2 & & 168,8 & 84,1 & 63,4 \\
\hline
\end{tabular}

Regarding the results obtained from the first heating scans, with the processing conditions applied, at initial times after samples be processed (Odays) neat PHB present lower values of crystallinity than the composites, except for U_AS. However, after 100 days of ageing the crystallinity of PHB increases about $20 \%$ due to secondary crystallization whilst the crystallinity 
of composites increases on average less than $10 \%$ achieving lower final crystallinity than PHB. This behavior can be attributed to hindered motion of the polymer chains because of the presence of the fibers as it has been reported in literature for PHA/fiber composites [51].

With respect to the fiber type or treatment, no remarkable differences have been found in crystallization and melting behavior. After full erasure of the thermal history, at low heating and cooling rates (such as current DSC conditions), thus allowing full crystallization to take place, all the samples present comparable values of enthalpy, crystallization and melting temperatures obtained from the cooling and second heating scans.

\section{$\underline{T G A}$}

The thermal stability of neat PHB and the composites was evaluated by thermogravimetric analysis (TGA). The weight loss as a function of temperature and their first derivative (DTG) curves are shown in Figure 10. The onset degradation temperature (T5\%), the maximum degradation temperature $(\mathrm{Td})$ and the residue at $600^{\circ} \mathrm{C}$ are summarized in Table 2. 

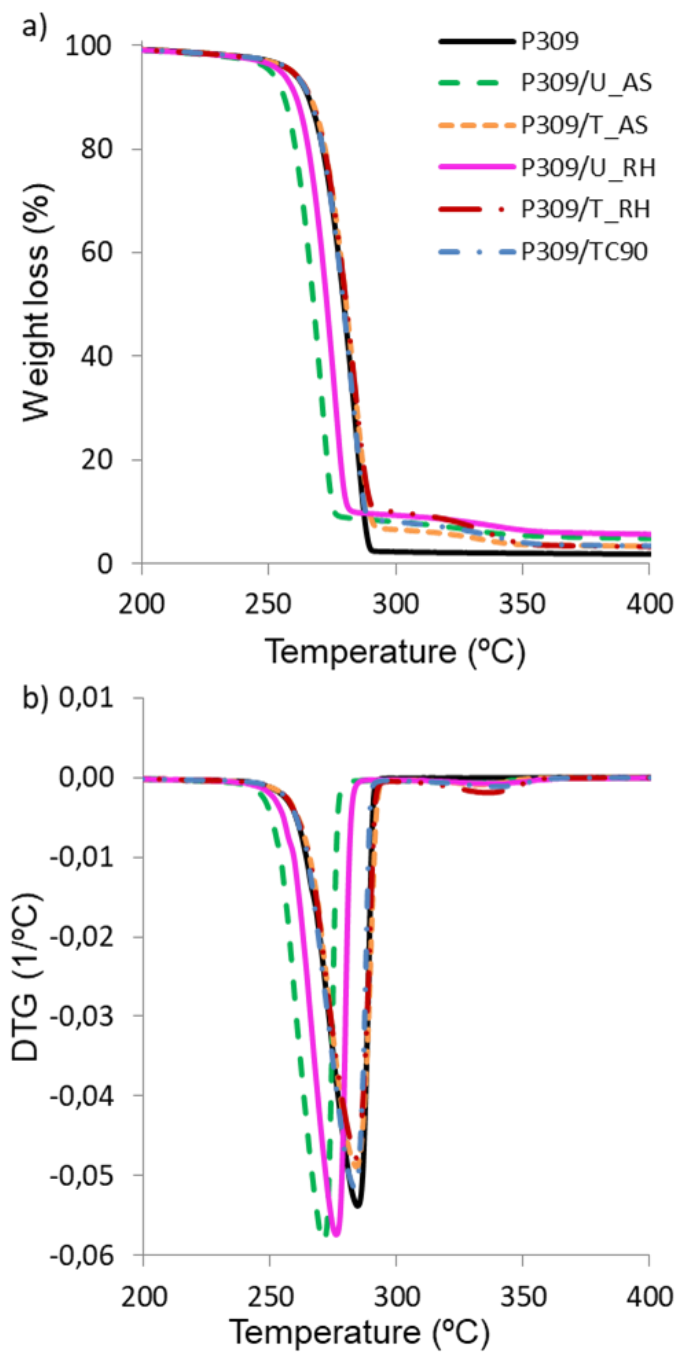

Figure 10. Weight loss (a) and DTG (b) curves corresponding to neat PHB and the composites.

Table 2. Thermal parameters obtained from TGA for neat PHB and the composites

\begin{tabular}{cccc}
\hline & $\mathrm{T}_{\mathbf{5} \%}$ (ㅇ) & $\mathrm{T}_{\mathrm{d}}$ (ㅇ) & residue (600ㄷ) \\
\hline PHB & 259 & 284 & 1,74 \\
PHB/U_AS & 251 & 271 & 4,27 \\
\hline PHB/T_AS & 259 & 284 & 2,8 \\
\hline PHB/U_RH & 255 & 276 & 5,08 \\
\hline PHB/T_RH & 259 & 284 & 2,9 \\
\hline PHB/TC90 & 259 & 283 & 3,11 \\
\hline
\end{tabular}

Thermal degradation of PHB takes place abruptly in a single weight loss step by a random chain scission mechanism as it has been widely reported [52]. The $T_{5 \%}$ and $T_{d}$ values for neat PHB are $259^{\circ} \mathrm{C}$ and $284 \stackrel{\circ}{\circ}$, respectively, and the residue at $600{ }^{\circ} \mathrm{C}$ is close to $2 \%$. On the other hand, the 
thermal degradation of the composites takes place in two steps. The second step, at approximately $345 \circ \mathrm{C}$, corresponds to the degradation of the cellulosic fibers. The treatment of the fibers has a clear positive influence on the thermal stability of the PHB. As shown in Table 2, for the composites containing the untreated fibers, both $T_{5 \%}$ and $T_{d}$ values are reduced with respect to neat PHB. This reduction is attributed to the presence of non-cellulosic components that starts their thermal degradation at lower temperatures than pure cellulose as discussed in fiber characterization section (see Figure 5). On the contrary, the incorporation of treated fibers does not affect the thermal stability of PHB (similarly to commercial cellulose). With respect to residue values at $600^{\circ} \mathrm{C}$, they are coherent with the fiber content and type, that is, the values are proportional to the fiber content and the higher values correspond to the untreated fibers according with the residues reported in fiber characterization section (Figure 5).

\section{Conclusions}

A combined $\mathrm{NaOH}+\mathrm{PAA}$ treatment was applied to AS and $\mathrm{RH}$ fibers in order to remove the noncellulosic components of the fibers and improve their surface characteristics to be used as reinforcing materials in PHB based composites taking as reference a commercial cellulose.

The combined $\mathrm{NaOH}+\mathrm{PAA}$ treatment has demonstrated its effectiveness in the removal of lignin and other non-cellulosic components such as hemicelluloses and waxes based on FTIR, WAXS and TGA results. The resultant fibers present comparable relative crystallinity indexes, chemical composition and thermal stability to the commercial cellulose. In addition, treated fibers present more reactive free $-\mathrm{OH}$ groups in their surface with respect to untreated ones as it has been observed by FTIR. Nevertheless, some differences were found regarding to their morphology. Treated RH presents fibrillary morphology with high aspect ratio, whilst treated AS presents irregular shape with high surface roughness. In both cases the treatment leads to a surface roughening with respect to untreated ones.

In general, all the fibers have a reinforcing effect on the PHB matrix as it has been deduced by the increased elastic modulus and storage modulus of the composites with respect to neat PHB. However, best results were found for treated fibers that allows overall performance similar to commercially purified cellulose. In case of untreated fibers, some detachment of the fibers has been observed in SEM (thus revealing poor adhesion on the interface) probably due to the presence of waxes and other impurities on their surface. For these composites, the tensile strength, elongation at break and $K_{I C}$ values are lower than those corresponding to the composites containing the treated fibers and TC90. In addition, the thermal stability of the 
composites with untreated fibers was slightly reduced with respect to neat PHB and the composites with treated fibers and commercial cellulose due to the presence of the noncellulosic components.

The effect of the fibers on the mechanical properties and crystallinity over time of the composites were also evaluated. The secondary crystallization and the physical ageing of PHB conduce to a drastic embrittlement of the matrix over time. As it has been observed by DSC the presence of the fibers partly hinder the development of crystallinity of PHB during ageing.

The incorporation of the fibers to the PHB does not seem to affect negatively to the mechanical behavior of the matrix once the aging has taken place, since the brittleness of the system is governed by the intrinsic fragility of the PHB matrix.

To conclude, a sustainable straightforward purification treatment has been applied to two different agro-food based lignocellulosic residues resulting in two suitable reinforcing fillers for a PHB matrix. An assessment of the environmental impact and the cost of applying this treatment to the abovementioned residues, with respect to the use of a commercially purified cellulose would determine whether its use is convenient for a particular application, attending to the fact that there are no main technical differences for its use as fillers in PHB matrix.

\section{Acknowledgments}

The authors would like to thank the financial support for this research from Ministerio de Ciencia, Innovación y Universidades (RTI2018-097249-B-C22), Pla de Promoció de la Investigació de la Universitat Jaume I (UJI-B2019-44) and H2020 EU Project YPACK (H2020-SFS-2017-1, Reference 773872). Authors would like to acknowledge the Instituto de Tecnología de Materiales of Universitat Politècnica de València-Campus de Alcoy, the Unidad Asociada IATAUJI "Polymers Technology" and Servicios Centrales de Instrumentación Científica (SCIC) of Universitat Jaume I. We are also grateful to Raquel Oliver and Jose Ortega for experimental support. 


\section{References}

1. Lambert, S., Wagner, M.: Environmental performance of bio-based and biodegradable plastics: The road ahead. Chem. Soc. Rev. 46, 6855-6871 (2017). https://doi.org/10.1039/c7cs00149e

2. Możejko-Ciesielska, J., Kiewisz, R.: Bacterial polyhydroxyalkanoates: Still fabulous? Microbiol. Res. 192, 271-282 (2016). https://doi.org/10.1016/j.micres.2016.07.010

3. Singh, M., Kumar, P., Ray, S., Kalia, V.C.: Challenges and Opportunities for Customizing Polyhydroxyalkanoates. Indian J. Microbiol. 55, 235-249 (2015). https://doi.org/10.1007/s12088-015-0528-6

4. Wang, Y., Yin, J., Chen, G.Q.: Polyhydroxyalkanoates, challenges and opportunities. Curr. Opin. Biotechnol. 30, 59-65 (2014). https://doi.org/10.1016/j.copbio.2014.06.001

5. Anjum, A., Zuber, M., Zia, K.M., Noreen, A., Anjum, M.N., Tabasum, S.: Microbial production of polyhydroxyalkanoates (PHAs) and its copolymers: A review of recent advancements. Int. J. Biol. Macromol. 89, 161-174 (2016). https://doi.org/10.1016/j.ijbiomac.2016.04.069

6. Laycock, B., Halley, P., Pratt, S., Werker, A., Lant, P.: The chemomechanical properties of microbial polyhydroxyalkanoates. Prog. Polym. Sci. 38, 536-583 (2013). https://doi.org/10.1016/j.progpolymsci.2012.06.003

7. Cava, D., Giménez, E., Gavara, R., Lagaron, J.M.: Comparative Performance and Barrier Properties of Biodegradable Thermoplastics and Nanobiocomposites versus PET for Food Packaging Applications. J. Plast. Film Sheeting. 22, 265-274 (2006). https://doi.org/10.1177/8756087906071354

8. Bugnicourt, E., Cinelli, P., Lazzeri, A., Alvarez, V.: Polyhydroxyalkanoate (PHA): Review of synthesis, characteristics, processing and potential applications in packaging. Express Polym. Lett. 8, 791-808 (2014). https://doi.org/10.3144/expresspolymlett.2014.82

9. Corre, Y.-M., Bruzaud, S., Audic, J.-L., Grohens, Y.: Morphology and functional properties of commercial polyhydroxyalkanoates: A comprehensive and comparative study. Polym. Test. 31, 226-235 (2012). https://doi.org/10.1016/j.polymertesting.2011.11.002

10. Liu, Q.-S., Zhu, M.-F., Wu, W.-H., Qin, Z.-Y.: Reducing the formation of sixmembered ring ester during thermal degradation of biodegradable PHBV to enhance its thermal stability. Polym. Degrad. Stab. 94, 18-24 (2009). https://doi.org/10.1016/j.polymdegradstab.2008.10.016

11. Mohanty, A.K., Vivekanandhan, S., Pin, J.M., Misra, M.: Composites from renewable and sustainable resources: Challenges and innovations. Science (80-. ). 362, 536-542 (2018). https://doi.org/10.1126/science.aat9072

12. Väisänen, T., Haapala, A., Lappalainen, R., Tomppo, L.: Utilization of agricultural 
and forest industry waste and residues in natural fiber-polymer composites: A review. Waste Manag. 54, 62-73 (2016). https://doi.org/10.1016/j.wasman.2016.04.037

13. Berthet, M.-A., Angellier-Coussy, H., Guillard, V., Gontard, N.: Vegetal fiberbased biocomposites: Which stakes for food packaging applications? J. Appl. Polym. Sci. 133, (2016). https://doi.org/10.1002/app.42528

14. Pereira, P.H.F., Rosa, M. de F., Cioffi, M.O.H., Benini, K.C.C. de C., Milanese, A.C., Voorwald, H.J.C., Mulinari, D.R.: Vegetal fibers in polymeric composites: a review. Polímeros. 25, 9-22 (2015). https://doi.org/10.1590/0104-1428.1722

15. Loureiro, N.C., Esteves, J.L., Viana, J.C., Ghosh, S.: Development of polyhydroxyalkanoates/poly(lactic acid) composites reinforced with cellulosic fibers. Compos. Part B Eng. 60, 603-611 (2014). https://doi.org/10.1016/j.compositesb.2014.01.001

16. Georgiopoulos, P., Christopoulos, A., Koutsoumpis, S., Kontou, E.: The effect of surface treatment on the performance of flax/biodegradable composites. Compos. Part B Eng. 106, 88-98 (2016). https://doi.org/10.1016/j.compositesb.2016.09.027

17. Satyanarayana, K.G., Arizaga, G.G.C., Wypych, F.: Biodegradable composites based on lignocellulosic fibers-An overview. Prog. Polym. Sci. 34, 982-1021 (2009). https://doi.org/10.1016/j.progpolymsci.2008.12.002

18. Basalp, D., Tihminlioglu, F., Sofuoglu, S.C., Inal, F., Sofuoglu, A.: Utilization of Municipal Plastic and Wood Waste in Industrial Manufacturing of Wood Plastic Composites. Waste and Biomass Valorization. 1-12 (2020). https://doi.org/10.1007/s12649-020-00986-7

19. Hejna, A., Sulyman, M., Przybysz, M., Saeb, M.R., Klein, M., Formela, K.: On the Correlation of Lignocellulosic Filler Composition with the Performance Properties of Poly( $\varepsilon$-Caprolactone) Based Biocomposites. Waste and Biomass Valorization. 11, 1467-1479 (2018). https://doi.org/10.1007/s12649-018-0485-5

20. Picard, M.C., Rodriguez-Uribe, A., Thimmanagari, M., Misra, M., Mohanty, A.K.: Sustainable Biocomposites from Poly(butylene succinate) and Apple Pomace: A Study on Compatibilization Performance. Waste and Biomass Valorization. 1-13 (2019). https://doi.org/10.1007/s12649-019-00591-3

21. Sánchez-Safont, E.L., Aldureid, A., Lagarón, J.M., Gámez-Pérez, J., Cabedo, L.: Biocomposites of different lignocellulosic wastes for sustainable food packaging applications. Compos. Part B Eng. 145, 215-225 (2018). https://doi.org/10.1016/j.compositesb.2018.03.037

22. Kumar, R., Hu, F., Hubbell, C.A., Ragauskas, A.J., Wyman, C.E.: Comparison of laboratory delignification methods, their selectivity, and impacts on physiochemical characteristics of cellulosic biomass. Bioresour. Technol. 130, 372-381 (2013). https://doi.org/10.1016/j.biortech.2012.12.028

23. Zhao, X., van der Heide, E., Zhang, T., Liu, D.: Delignification of sugarcane bagasse with alkali and peracetic acid and characterization of the pulp. BioResources. 5, 1565-1580 (2010) 
24. Mariano, M., Cercená, R., Soldi, V.: Thermal characterization of cellulose nanocrystals isolated from sisal fibers using acid hydrolysis. Ind. Crops Prod. 94, 454-462 (2016). https://doi.org/10.1016/j.indcrop.2016.09.011

25. Segal, L., Creely, J.J., Martin, A.E., Conrad, C.M.: An Empirical Method for Estimating the Degree of Crystallinity of Native Cellulose Using the X-Ray Diffractometer. Text. Res. J. 29, 786-794 (1959). https://doi.org/10.1177/004051755902901003

26. Brown, R.: Fracture Mechanics Testing Methods for Polymers Adhesives and composites. Polym. Test. 21, 363 (2002). https://doi.org/10.1016/S01429418(01)00080-0

27. Carli, L.N., Crespo, J.S., Mauler, R.S.: PHBV nanocomposites based on organomodified montmorillonite and halloysite: The effect of clay type on the morphology and thermal and mechanical properties. Compos. Part A Appl. Sci. Manuf. 42, 1601-1608 (2011). https://doi.org/10.1016/j.compositesa.2011.07.007

28. Arjmandi, R., Hassan, A., Majeed, K., Zakaria, Z.: Rice Husk Filled Polymer Composites. Int. J. Polym. Sci. 2015, (2015). https://doi.org/10.1155/2015/501471

29. Khiari, R., Mhenni, M.F., Belgacem, M.N., Mauret, E.: Valorisation of Vegetal Wastes as a Source of Cellulose and Cellulose Derivatives. J. Polym. Environ. 19, 80-89 (2011). https://doi.org/10.1007/s10924-010-0207-y

30. Paschoal, G.B., Muller, C.M.O., Carvalho, G.M., Tischer, C.A., Mali, S.: ISOLATION AND CHARACTERIZATION OF NANOFIBRILLATED CELLULOSE FROM OAT HULLS. Quim. Nova. 38, 478-482 (2015). https://doi.org/10.5935/0100-4042.20150029

31. Battegazzore, D., Bocchini, S., Alongi, J., Frache, A., Marino, F.: Cellulose extracted from rice husk as filler for poly(lactic acid): preparation and $\begin{array}{lllll}\text { characterization. } & \text { Cellulose. } & \text { 21, } & \text { 1813-1821 }\end{array}$ https://doi.org/10.1007/s10570-014-0207-5

32. Urruzola, I., Robles, E., Serrano, L., Labidi, J.: Nanopaper from almond (Prunus dulcis) shell. Cellulose. 21, 1619-1629 (2014). https://doi.org/10.1007/s10570014-0238-y

33. Duan, L., Yu, W., Li, Z.: Analysis of structural changes in jute fibers after peracetic acid treatment. J. Eng. Fiber. Fabr. 12, 33-42 (2017). https://doi.org/10.1177/155892501701200104

34. Ndazi, B.S., Karlsson, S., Tesha, J. V., Nyahumwa, C.W.: Chemical and physical modifications of rice husks for use as composite panels. Compos. Part A Appl. Sci. Manuf. 38, 925-935 (2007). https://doi.org/10.1016/j.compositesa.2006.07.004

35. El Mechtali, F.Z., Essabir, H., Nekhlaoui, S., Bensalah, M.O., Jawaid, M., Bouhfid, R., Qaiss, A.: Mechanical and Thermal Properties of Polypropylene Reinforced with Almond Shells Particles: Impact of Chemical Treatments. J. Bionic Eng. 12, 483-494 (2015). https://doi.org/10.1016/S1672-6529(14)60139-6

36. Chanda, A.K., Hazra, A., Praveen Kumar, M., Neogi, S., Neogi, S.: Chemical treatments of rice husk filler and jute fiber for the use in green composites. Fibers 
Polym. 16, 902-910 (2015). https://doi.org/10.1007/s12221-015-0902-3

37. Johar, N., Ahmad, I., Dufresne, A.: Extraction , preparation and characterization of cellulose fibres and nanocrystals from rice husk. Ind. Crop. Prod. 37, 93-99 (2012). https://doi.org/10.1016/j.indcrop.2011.12.016

38. Paulo, J., Oliveira, D., Pinheiro, G., Oliveira, K., Lisie, S., El, M., Silveira, G., Renato, A., Dias, G., Zavareze, R.: Cellulose fibers extracted from rice and oat husks and their application in hydrogel. Food Chem. 221, 153-160 (2017). https://doi.org/10.1016/j.foodchem.2016.10.048

39. Rosa, S.M.L., Rehman, N., Miranda, M.I.G. De, Nachtigall, S.M.B., Bica, C.I.D.: Chlorine-free extraction of cellulose from rice husk and whisker isolation. $\begin{array}{llll}\text { Carbohydr. } & \text { Polym. } & \text { 87, } & \text { 1131-1138 }\end{array}$ https://doi.org/10.1016/j.carbpol.2011.08.084

40. Yang, H., Yan, R., Chen, H., Lee, D.H., Zheng, C.: Characteristics of hemicellulose, cellulose and lignin pyrolysis. Fuel. 86, 1781-1788 (2007). https://doi.org/10.1016/j.fuel.2006.12.013

41. Tobergte, D.R., Curtis, S.: Biocomposites: Desing and Mechanical Performance. Elsevier Inc. (2013)

42. Michael A. Gunning, Luke M. Geever, John A. Killion, John G. Lyonsa, C.L.H.: Mechanical and biodegradation performance of short natural fibre polyhydroxybutyrate composites. Polym. Test. 32, 1603-1611 (2013)

43. Torres-Tello, E. V., Robledo-Ortíz, J.R., González-García, Y., Pérez-Fonseca, A.A., Jasso-Gastinel, C.F., Mendizábal, E.: Effect of agave fiber content in the thermal and mechanical properties of green composites based on polyhydroxybutyrate or poly(hydroxybutyrate-co-hydroxyvalerate). Ind. Crops Prod. 99, 117-125 (2017). https://doi.org/10.1016/j.indcrop.2017.01.035

44. Fei, B., Chen, C., Chen, S., Peng, S., Zhuang, Y., An, Y., Dong, L.: Crosslinking of poly[(3-hydroxybutyrate)-co-(3-hydroxyvalerate)] using dicumyl peroxide as initiator. Polym. Int. 53, 937-943 (2004). https://doi.org/10.1002/pi.1477

45. Srubar, W. V., Wright, Z.C., Tsui, A., Michel, A.T., Billington, S.L., Frank, C.W.: Characterizing the effects of ambient aging on the mechanical and physical properties of two commercially available bacterial thermoplastics. In: Polymer Degradation and Stability. pp. 1922-1929 (2012)

46. Esposito, A., Delpouve, N., Causin, V., Dhotel, A., Delbreilh, L., Dargent, E.: From a Three-Phase Model to a Continuous Description of Molecular Mobility in Semicrystalline Poly(hydroxybutyrate-co-hydroxyvalerate). Macromolecules. 49, 4850-4861 (2016). https://doi.org/10.1021/acs.macromol.6b00384

47. Sánchez-Safont, E.L., González-Ausejo, J., Gámez-Pérez, J., Lagarón, J.M., Cabedo, L.: Poly(3-Hydroxybutyrate-co-3-Hydroxyvalerate)/Purified Cellulose Fiber Composites by Melt Blending: Characterization and Degradation in Composting Conditions. J. Renew. Mater. 4, 123-132 (2016). https://doi.org/10.7569/JRM.2015.634127

48. Turi, E.A.: Thermal characterization of polymeric materials. Academic Press 
$(1981)$

49. Saba, N., Jawaid, M., Alothman, O.Y., Paridah, M.T.: A review on dynamic mechanical properties of natural fibre reinforced polymer composites. Constr. Build. Mater. 106 , $149-159$ (2016). https://doi.org/10.1016/j.conbuildmat.2015.12.075

50. Wong, S., Shanks, R., Hodzic, A.: Interfacial improvements in poly(3hydroxybutyrate)-flax fibre composites with hydrogen bonding additives. Compos. Sci. Technol. 64, 1321-1330 (2004). https://doi.org/10.1016/j.compscitech.2003.10.012

51. Wu, C.S.: Preparation and Characterization of Polyhydroxyalkanoate BioplasticBased Green Renewable Composites from Rice Husk. J. Polym. Environ. 22, 384392 (2014). https://doi.org/10.1007/s 10924-014-0662-y

52. Grassie, N., Murray, E.J., Holmes, P.A.: The thermal degradation of poly(-(d)- $\beta$ hydroxybutyric acid): Part 2-Changes in molecular weight. Polym. Degrad. Stab. 6, 95-103 (1984). https://doi.org/10.1016/0141-3910(84)90075-2 